\title{
Introduction: Exploring Power for Change
}

\author{
Rosalind Eyben, Colette Harris and Jethro Pettit
}

\begin{abstract}
1 Linking participation with power
Concepts and methods of 'participation' are used increasingly throughout the world in shaping policy and in delivering services. At the Institute of Development Studies (IDS) we are finding that these participatory approaches throw new light on the complex interactions within and between society and state institutions at local, national and global levels. Participatory approaches lead to questions about how different kinds of knowledge and values shape the rules of the game and policy choices. What are the societal and political processes through which power operates that inform whose voice is heard and whose is excluded? This then leads to asking what is power? Is it just about someone making other people act against their best interests? Or, is it also the glue that keeps society together? What are the connections between power and social change?

To make explicit that these are the questions at the core of our research and teaching interests, the Participation Group at IDS has recently changed its name to 'Participation, Power and Social Change'. And, in keeping with that name change, this issue of the IDS Bulletin aims to present some of our current work on the practice of power in development and on the entry points for change. Much of this work has been supported by a programme of action research and capacity building funded between 2003- 6 by the Department for International Development (DFID), the Swedish International Development Agency (Sida) and the Swiss Agency for Development and Cooperation (SDC), and the contributions explicitly or otherwise reflect our dialogue with colleagues in these agencies as well as more broadly with our many partners in civil society and research institutes, primarily in the South, but also in the North.
\end{abstract}

Our proposal to our donors in 2003 argued that despite some positive changes at the global level growing social initiatives and civil experiments, the recent explosion of processes of democratisation, and increasing openness by governments and the private sector to being held accountable - global economic and political factors are entrenching poverty and inequality and reducing the agency of citizens to influence the processes that affect their lives. We suggested that this is partly because people living in poverty are cut off from real avenues of power and argued that the realisation of people's rights will depend in part on forging links of solidarity between people and organisations at different levels so that they can better understand the dynamics of power between citizens and government, and within global and national institutions - with a view to changing them.

Thus, over the last few years, our work on participation has focused on the perspectives of those who are living in poverty and struggling to claim their rights and on the organisations who claim to be supporting these struggles. Concerning the first, we have been exploring issues of power from the perspective of those who are grappling to understand what is happening to them in their own lives. In this IDS Bulletin, Colette Harris' article on power and gender relations in Mali and Joy Moncrieffe's on children in Haiti are examples of such work and include an exploration of the possibilities for empowerment by those they are writing about. At a more general level, John Gaventa and Andrea Cornwall's article on participation, knowledge and power looks at how such research can contribute to popular awareness-raising and political mobilisation. They also consider the challenges to participatory action research (PAR) when seeking to bring the realities of poor people's lives, as they understand them, to the notice of those organisations which claim to be working on behalf of these people.

A better understanding of the operations of power for those struggling to realise their rights is equally 
important for those organisations with a global reach and which have the capacity to affect the lives of many - for good or for ill. However, progressive change that leads to greater equity and social justice is often subject to contestation. People living in poverty may have diverse political agendas, while those who are wealthy will act to defend their interests. Official aid agencies as well as international non-governmental organisations (NGOs) are gaining an enhanced appreciation of politics and national context, but if they work without any clear conceptual understanding of how power may work in development practice and within their own operations, they may be unknowingly perpetuating the inequity and injustice they are striving to change. Cathy Shutt and Rosalind Eyben explore these issues from the perspective of their own erstwhile positions from within the international aid system.

As we go on to discuss, power can be conceptualised in many different ways giving rise to different sets of debates (Mosse 2005). For some, 'power' is normally associated with the state and formal political institutions. DFID, for example, is currently inviting expressions of interest in relation to a new research programme on 'Power, Politics and the State' in which the issues are framed in terms of 'elites, elections, parliaments, political stakeholders, rule of law, etc.' (DFID 2006). In contrast, the focus of this IDS Bulletin is more on informal power that is dispersed throughout society and operates in all relationships and how that shapes and is shaped by political and other social institutions. For example, both Hunter and Harris look at power and gender relations within families; Taylor and Boser explore power within institutions of higher education; Navarro within a social movement and both Eyben and Shutt within international aid.

The DFID research programme just mentioned understands the debate about power as a question of how 'countries and their governments balance the short term needs for responsiveness against the longer term requirements of a transformative agenda, and how the interplay of political and institutional forces influences the choice of routes to development' (DFID 2006). In this IDS Bulletin, however, contributors' interest in the wider operations of power highlights other tensions. One of these, debated with the Participation Team's international advisory group at a meeting in 2004, concerns the significance of personal transformation for changing power relations within the wider society. Another relates to whether power can be harnessed to secure win-win outcomes without any losers, in a process of securing greater equity and social justice or whether power relations change because of contestation and challenge to the existing order. Later in this introduction, we discuss how these debates are couched in the contributions to this IDS Bulletin.

Thus this IDS Bulletin reflects the different ways we have been working with and studying the diverse sets of development actors and relations mentioned in the preceding paragraphs. Starting with the premise that there is nothing as practical as good theory, our experience with participatory approaches to development has led to some preliminary explorations of power in development relationships. In so doing, we recognise that there are many ways in which we can understand power. Depending on actors, the issue and the historical context, different concepts of power may be more or less helpful in illuminating entry points for change. Bearing this in mind, what have we learnt so far?

\section{Conceptualising power}

Robert Chambers in this IDS Bulletin notes that power is a useful word because it has a commonsense, rather than a difficult academic meaning. Nevertheless, power is a contentious, sometimes even threatening word in the world of development research and practice. It is contentious because, as a concept, we can understand it in many different ways and debates about meanings may remain fruitless should they stay at a theoretical level. It is also contentious because these different understandings are themselves shaped by power. When presented in a way that would appear to challenge people's perceptions of the way the world is, or the way they think it should be, talking about power may be threatening. For example, we have found that in some bilateral aid organisations, the word may trigger alarm, particularly when going beyond the analysis of formal political institutions to exploring informal power that is dispersed throughout society and operates in all relationships. Thus, power may resist its naming. Conversely, for those who evoke it, that same action of naming power may be empowering.

Power can be thought of as capacity - an idea originating with Weber - and as such can be 
understood as both enabling social change and sustaining the status quo (Hindess 1996). From this perspective, the idea that power drives the development process is not new. Yet the naming and analysis of power - as fundamental in the multiple sets of relationships that shape development practice - is still relatively recent. Still being explored is whether and how conceptual and applied understandings of the operations of power can help development actors (including governments, civil society and grassroots organisations, research and teaching institutes and international development agencies) in their efforts to reduce global poverty and make progress towards social justice. This IDS Bulletin aims to contribute to such an exploration, also bearing in mind the mission and vision of the IDS that includes:

- a concern for equity and social justice as well as for poverty reduction

- an explicit recognition of the power relations that shape development processes

- a vision of a world in which citizens have greater power to influence the state and private institutions to work in ways that accelerate poverty reduction and promote social justice. (IDS Annual Report 2004-05)

As will become apparent when reading the articles, the contributors - nearly all members of the Participation, Power and Social Change Team - apply different understandings of power. This diversity is partially explained by our various personal histories, ideological positions and disciplinary backgrounds. However, it also derives from our recognising the utility of different conceptual approaches for exploring and explaining diverse contexts as well as engaging with differently positioned development actors. Most of us in the team do not work on the premise that there is a one-size-fits-all theory of power for achieving social change. Nevertheless, in his article, Zander Navarro is perhaps more explicitly attached to the possibility of a 'meta-theory that allows us to understand power structures and power relations in any given context' - although he extols the subject of his article, the French sociologist Bourdieu, for not claiming to offer an overall theory of social change. At the same time, the explanatory power of Bourdieu is evident in this IDS Bulletin, not only in Navarro's article where he explores Bourdieu's theory in relation to the landless movement in Brazil but also in the articles by Taylor and Boser, Moncrieffe, and Eyben. Navarro argues that social activists would profit from a serious study of social theory and cautions against an oversimplistic use of toolkits and frameworks to support action for social change.

On the other hand, developing and critiquing theories of power has also been judged by some (but not all) of our civil society partners in the South as running the risk of becoming too theoretical. An independent evaluation of our work earlier this year wondered whether the challenge was one of how to balance the pressure for academic publications required by UK research assessments, with the needs of Southern stakeholders (and some Northern ones) for less academic and more practical, hands-on guides to development practice. But that same evaluation encouraged us by recommending that the theoretical underpinnings of our work on power need to be made clearer and the practical applications better demonstrated. ${ }^{1}$ The Gaventa framework - the 'power cube' has been deliberately designed to be accessible as an analytical tool for practitioners as well as researchers. As such, it has been well received, both by civil society activists and donor agencies, including DFID and the SDC.

We doubt that we are much driven by the pressure for academic publications but do recognise an important and necessary tension in the team's research between on the one hand, engaging through action research and learning with those struggling for their rights - simplifying theory as a tool for thinking with - and, on the other hand, developing and critiquing theory as a means for greater understanding of how power operates. We believe we need to do both and hope that this IDS Bulletin reflects this dual purpose. In his second article, written with Cornwall, Gaventa specifically explores some of the quandaries relating to the role of knowledge in supporting social change.

Despite different approaches on this matter of theory and frameworks, the contributors also share much in common. First of all, is a commitment to praxis - the notion of empowered individuals and groups engaging with and applying theory as a tool to help shape the kind of world they want for themselves and for future generations of society. Related to this is a concern for reflective research, teaching and action. This means enquiring critically into how we learn about the world and reflecting 
on how power shapes our modes of being, learning and action. Critical reflection - becoming knowingly conscious of ourselves - provides the means for interrogating prevailing interpretations of our social world and ways of behaving within it by asking 'Can it not be otherwise?'.

Experiential learning and reflective practice potentially challenge the social consensus of 'this is the way things are done around here' and several contributions explore power as created by tacit knowledge that is acquired and reinforced through disciplinary practices. Yet even when we become conscious that this is happening, we may decide to not to contest such norms because on balance we see them as being in our best interests. This is where the notion of consensual power comes from (Haugaard 2003). Arendt's notion of 'authority' relates to this, with examples from Plato of - among other relationships - that between the physician and the patient (Arendt 2003).

Conversely, some contributors see the exposure of power as a step towards challenging power. Here, power is understood as 'power over' created by the social order, backed up by the threat of coercion - or even in the case of Hunter's article, the actual use of violence through which men individually and collectively uphold their dominant position. In the light of such a conceptual approach, responses to power may be either to let those dominating have their way because of lack of critical consciousness (the power is internalised), or to be aware of what is happening and choose not to resist (as noted above), or to be aware and choose to resist - either subversively or openly depending on the circumstances and opportunity. Strategic questions then arise about the particular processes or interventions (e.g. legislation, emancipatory forms of education, development of critical self-awareness and self-esteem, advocacy, social mobilisation, etc.), which can be effective in revealing and challenging power in its less visible and more embedded forms.

Lastly, another view of power, important to many of the contributors, is that of power as capability - and thus power as potentially infinitely expanding. The view here is that through deliberative dialogue and other participatory modalities a greater number of people including those who historically had less voice may join the debate and secure an agreement that things could be done differently, amplifying our imagination of what is possible. Assumptions concerning the potential for power to expand in such a manner must however take into account the role of discourse. If people's understanding of what is possible is shaped by the historical and cultural context of which they are part, it is very difficult to conceive social relations differently even when new spaces for deliberation are opened up.

The rest of this introduction discusses how these themes and views on power are explored and debated in this IDS Bulletin. First, we look at how the contributors approach reflective practice, including how they explain to themselves and their readers why it is they are interested in power. We then turn to a discussion of consensual power, followed by thinking about power as challenged or contested, associated with efforts to shift power relations. Whereas both of these latter two approaches may be understood as seeing power as a finite resource, in contrast, when associated with ideas of participatory, inclusive democracy, power may not be seen as a finite resource with politics determining its distribution. Instead, power may be seen as something each one of us possesses - a power within that may be liberated and therefore relatively infinite. We discuss this approach under the rubric of expanding power. For the last theme, we return to the idea of reflective practice but look more deeply at how forms of critical reflexive learning may contribute to transforming power in social relations. We conclude by posing some questions for ourselves. What are the implications of these various ways of exploring power for our future work and for the IDS mission and vision?

\section{Experiencing and reflecting on power}

'Reflexivity' is a word that appears fairly frequently in the work of the Participation team, as well as in this IDS Bulletin. Navarro refers to the importance of sociology being a reflexive discipline, meaning that social theorists should enquire as to how society and culture shape their modes of inquiry and ways of knowing about that society and culture into which we are inquiring. Thus we need to be alert as to how the politics of culture determines the extent of our imagination and hence our observation. Similarly, Eyben argues that if those involved in aid relationships were more familiar with gift theory they might be better equipped to understand how power is working in that relationship and learn to better manage the shadow side of the gift. Likewise, Taylor and Boser 
reflect on how the operations of power in institutes of higher education can neutralise or undermine the hoped for transformation in students' understanding and practice that participatory pedagogy aspires for in the classroom. Here they make a case for reflexivity based on a consideration of how institutes of higher education, such as IDS, are shaped by the wider global society of which we are part and to which we also contribute.

This academic reflexivity is taken further by Taylor and Boser and other contributors interested in how they have experienced power in their personal and professional lives. For some, it has indeed been these direct experiences of power that have contributed to shaping the contributors' intellectual and political approach to the subject. Gaventa's early experiences of what, in conversation with the editors, he has referred to as 'hard' power, has shaped his strong commitment to both understanding and challenging a power that results in intimidation and injustice. By recalling, articulating and acknowledging their experiences, not only intellectually, but as Jethro Pettit emphasises, through experiential and emotional recollection, others, such as Shutt and Eyben have sought to reflect critically on their own power, looking back on and questioning their own past behaviour. As Shutt comments, while this kind of reflection might seem a kind of vanity, it proves to be painful.

Feminist perspectives have influenced this reflexive approach to power, appearing most strongly in Pettit's article where he examines not only who he is and how this shapes his understanding but the role of power in shaping how he is at different moments. Identity shifts affect one's understanding of power, as Eyben describes the physical sensations she felt when she found herself sitting at the other side of the table, no longer an official donor but part of a small civil society organisation asking for funds. However, acknowledging one's own position and seeking to adapt one's behaviour to diminish power differences can only take one so far, as Colette Harris discusses in her article on working within a Malian rural community.

Reflexivity is associated with the idea of critical or discursive consciousness - that ability to step out of your identity and interrogate how that identity shapes your understanding of what is possible, in other words what is power. As we discuss in the final section to this introduction, it is such a consciousness that offers the possibility of transforming social relationships through one's own changed behaviour, for example Rosa Parks, a leader of the American black civil rights movement who refused to give up her seat to a white passenger. What Haugaard (1997), one of the best modern writers on power, describes as an infelicitous action (one that society would judge as either mad or bad) became felicitous as a result of the widespread prior mobilisation and protests taking place that gave Parks the courage to make her gesture (Lovell 2003). Yet, such consciousness that the world could be otherwise does not always lead to changing behaviour and people may consent to the power of the existing social order even if they think it unjust. In an unpublished paper, Tony Klouda (2004) of Care International queries whether most people are prepared to go through such a process of changing their understanding of how they view the world and their position in it because of the risk to their livelihoods and their sense of belonging and position in society.

\section{Consenting to power}

Do people consent to power because they are aware of their situation and feel they have no choice? Or are they socialised not to challenge power? Joy Moncrieffe explores this question with reference to Haitian society and concludes that while some victims of class and racial discrimination accept and internalise the stigma power imposes upon them - what Gaventa refers to as 'invisible power' others still have and exercise their capacity to resist and even dominate some spaces. For example, as Harris discusses elsewhere, women who acquiesce to established power relations may well find themselves more disadvantaged than those who resist (Harris 2004).

In his article on Bourdieu, Navarro uses the term 'misrecognition' to describe the process of mystification by which the powerful use their symbolic capital to prevent individuals from recognising that their subordination is culturally constructed rather than 'natural'. He argues that sociology transforms power because of its potential to reveal this process and thus liberate people from their misconceptions. The idea that power can be wielded culturally as well as economically so that people consent willingly to it chimes with Cathy Shutt's personal account of her time as a development volunteer in the Philippines. There from 
her position as an expatriate aid worker she accumulated what Bourdieu would describe as symbolic capital by learning to speak 'Aidlish' and mystify her local colleagues through her dexterity with logical framework analysis and other artefacts of Aidland. Shutt comments on how this symbolic power was enhanced by her own belief in the merits of such artefacts, leading to the question as to whether being legitimate in the eyes of others means you must yourself be a believer.

However, as Moncrieffe points out, not everyone reacts in the same way to mystification processes. People may not be mystified - they may not have internalised power - but on the contrary may have rationally decided that in the circumstances it is in their best interests to consent to, rather than contest power. Such a decision may be one based on fear of the possibly violent consequences should they challenge power. But it can be argued that for sustaining the social order, brute coercion is very much a last resort that is likely to be untenable over time (Haugaard 2003). The exception to this argument are those situations where violence has become embedded in everyday social processes. Domestic violence is a leading example of this.

If violence becomes an institutionalised form of power, as in Haiti, it creates continuous instability and injustice. Moncrieffe provides a vivid and depressing account of how power operates in that country through a combination of violence and stigma - the 'power of labelling', which is reproduced in the socialisation of children, including those living on the street who learn to adapt or develop subcultures of contestation.

The socialisation of violence is also a theme of Hunter's article. Taking the case of South Africa, she discusses how the family can be a mechanism for socialisation in which women can be complicit in perpetuating patriarchal values including the socially condoned practice of violence against women. In such a context, the power of a benign state can be harnessed as a counterbalance but efforts through legislation to reduce the practice of violence may be limited in impact when societal forms of social control remain unchallenged.

Thus, the question remains as to the extent to which in most places at most times, social order is dependent upon people consenting to power, either knowingly or unknowingly, and adapting to it. Robert Chambers, like Arendt, argues that there is nothing necessarily bad in one person having power over another; it all depends what they do with that power. In her analysis of power and gender relations in a Mali village, Harris stresses that the superior power position conferred upon men is a result of 'traditional methods of maintaining social order' (what Bourdieu would describe as habitus) that are accepted and confirmed by all concerned. From this perspective, even if people become conscious of the cultural construction of power (that is they are not mystified by it), they may accept the societal arrangements for the sake of the stability and security that these provide. This means accommodating power and deciding that the shortterm benefits are worth more than radical change in the future. Thus, Eyben discusses how recipients of international aid are in a typical client relationship with more powerful patrons. By taking aid, which they badly need, they confirm the economic and symbolic dominance of the donor and hence the current world social order that aid flows help to sustain. On the other hand, her case study shows how those in power in the recipient government in fact managed to avoid in practice what they had been obliged to agree to in principle and to convert to other ends much of the money destined for greater popular participation.

Consenting to the power of the prevailing social order as noted with reference to Moncrieffe's study, may imply adapting while resisting through what De Certeau (1988) and Scott (1987) refer to as the everyday tactics of the weak over the strong. Thus Harris notes while tradition in rural Mali gives all men power over all women, there is also another more silent tradition by which older women have power over younger men although this is not openly discussed. If it were to be openly acknowledged, such 'tacit' power may harder to maintain.

As Moncrieffe discusses, individuals or groups who learn how to take advantage of the existing societal arrangements can become quite powerful - leaders of street gangs, for example - in circumstances which would seem culturally to disfavour them. This poses a conundrum for teachers and social activists. Should they encourage critical inquiry into prevailing inequality and injustice or enable people to learn how to make the best of their existing situation? (Hayward 2000). Navarro argues that if the leaders of the 
Brazilian landless movement had studied Bourdieu they would not have established arrangements for the collective management of the sequestered land because such arrangements released women's labour from the control of their husbands, and by challenging the prevailing cultural traditions of patriarchy created a resistance among the movement's followers to farming along cooperative lines with resulting low levels of productivity. While clearly not supporting the continuance of patriarchy, Navarro poses an interesting question as to the extent to which a social movement should challenge all aspects of prevailing power in circumstances where this might be detrimental to the movement's members' capacity to secure sustainable livelihoods. In which case, as Gaventa asks, which are the optimal spaces for change in challenging power? And who decides what is optimal?

\section{Contesting power}

Our team's experiences with participatory approaches to development have led us to explore power and relationships from diverse perspectives. As Gaventa discusses, we have learnt that spaces for participation are not neutral but are themselves shaped by relations of power that both surround and enter them. This view of power as relational, shared by all contributors to this IDS Bulletin, has implications for strategies for challenging power and contrasts with another view of power common in various disciplines. In international relations, for example, power is often understood as a resource - economic, military, human - which is finite in its availability and is wielded to exert domination. Human history is viewed as the story of competition for distribution and redistribution of these resources. Navarro in analysing Bourdieu sees power in this way as well, but with the very important proviso that the resource - or capital - is culturally constructed through social relations. Thus resources have no intrinsic value other than the meaning we ourselves give to them and it is symbolic capital that determines the meaning, and therefore the value, of resources. Thus a radical way of challenging power is to deny its legitimacy.

Understanding power as constructed through patterns of social relations that are reproduced through processes of socialisation provides an agenda for contesting power that concerns changing the way people relate to each other - including changing the meanings they give to these relationships.
Robert Chambers uses the language of 'uppers' and 'lowers' to describe situations in which one person has power over another, while stressing that a person may be an 'upper' in one context and a 'lower' in another. Gaventa in his article on entry points for change starts from the position of looking at the institutional and cultural structures that enable domination. Using the idea of 'three faces of power' - visible, hidden and invisible - he suggests that political processes are shaped not just by contests over (visible) interests that take place in observable or public spaces but also by the structures of relations that set the rules of the game (or hidden structures) so that some have more power than others to influence outcomes, as well as by invisible power already discussed. Gaventa then takes Chambers' idea of context and turns this into concepts of 'space' and 'place'. By 'space' he means the ways in which participation or political engagement occurs, for example whether power is contested in formal parliamentary institutions or through autonomous social movements; by 'place' he means the arenas of political struggles, from the very local level of the family or community up to national and even global levels.

When power is seen as a finite resource, inevitably the history of humanity will be one of contest. If we see contestation as 'natural' or inevitable then it becomes a self-fulfilling prophecy. But what if power were understood more like a balloon that can be infinitely expanded? Could we explore power for change by looking for entry points towards achieving harmonious and equitable social relations? Although Gaventa sees power primarily in terms of conflict or contestation, both he and Chambers are interested in the idea of how spaces for participation can expand power so that more people have it, with Chambers being more interested in how this can be achieved without anyone losing out, as we now go on to discuss.

\section{Expanding power}

Not seeing power as a zero-sum game has long been a preoccupation of Chambers who argues that positive change can be more easily achieved through identifying win-win situations (Saxena et al. 1989). In his article in this IDS Bulletin, he comments that by assuming that power is never given up without a fight, those struggling for social justice may be missing important opportunities for engaging with the powerful. An example would be working with 
decision-makers on the assumption that they are trying their best but are constrained by the inadequacies of their own bureaucratic organisations. Resistance can be reduced by inviting more people to help them seize such opportunities.

Understanding power in this way is underpinned by a normative preference for cooperation rather than competition. As such, it has a very long philosophical history. This includes a strand in feminist understandings of the political that emphasises that the value of the common good as achieved through democratic sharing and participation, in contrast to a liberal concept of democracy, as being an arena where competing interests come to some kind of bargain or settlement about the balance of power in society (Mouffe 1997). Conversely, Hunter's study of the passing of the Prevention of Family Violence Act in South Africa in 1993 reveals the complexity of any particular attempt to change societal power relations, with both the expansion of power through new coalitions of women across political divides and political opportunism by an authoritarian party desperately seeking new voters.

Taylor and Boser pursue a similar line of thought when seeking to avoid thinking of power relations in terms of them and us, which can be particularly challenging when those resisting change are acting in an adversarial fashion. Yet, they argue, if one is capable of learning not to internalise the conflict and not to counter aggressive power with a further aggressive reaction, there are real possibilities of achieving greater participation and more equal power relations within organisations such as institutions of higher education. Approaches to learning that aim to transform society would thus be reinforced by the day-to-day practice of the staff, enhancing the possibility that their students in turn might be agents of change in their future careers as development actors.

Gaventa's idea of expanding power, on the other hand, makes no assumptions that someone else does not have to give it up. Rather he suggests strategies for expanding power among those who are currently powerless, for example through building horizontal alliances that link up different spatial entry points for change. However, he stresses that without prior awareness, building such new strategies for expanding power may be captured by prevailing interests. This idea of raising awareness, encouraging critical reflection or discursive consciousness, runs through all the contributions to this IDS Bulletin, to which we finally turn.

\section{Transforming power}

Many people in a subordinate position may question the way the world is ordered but do not organise themselves for strategic resistance because of the fear of the consequences should they fail. They would need to gain support from others to develop new ways of understanding - or frameworks of meaning - about how the world could work. What are the conditions that allow for the mobilisation of such support? Power with is a term that has been coined to refer to the building of common ground among different interests, the development of shared values and strategies and the creation of collective strength through organisation (Rowlands 1997). Power with depends on individuals and groups releasing their power within through a process of self interrogation or consciousness raising.

Empowerment frameworks have been developed by activists that draw on these concepts of power and can serve as guides to action, including the likely risks in applying these (Veneklasen and Miller 2002). One such risk is pointed to by Shutt who comments that whether one's actions from a position of power to support empowerment are interpreted as helpful and creating power to or trying to gain control (power over), is highly subjective and is shaped by the beliefs and values of those one is seeking to help.

Chambers, an avowed optimist, argues that through a 'pedagogy of the powerful' power over can be used as an empowering opportunity for both themselves and those they are seeking help; 'with less power goes a better experience of life'. Harris uses a Socratic approach of asking questions, setting off a train of self enquiry leading to changed behaviour. However, she does not necessarily agree with Chambers that men, when 'uppers' in a relationship with women, are likely to voluntarily give up power.

In both cases however, it is an approach to learning that encourages self scrutiny. Both Pettit's and Taylor and Boser's articles focus on the importance of teachers and facilitators themselves reflecting on their power in promoting wider learning for change. Pettit emphasises the benefits of cyclical and experiential methods that can help educators and those they are learning with to understand power not just conceptually and cognitively but through the 
senses, emotions, creativity, intuition and embodied forms of knowledge as means of accessing and transforming power. On the other hand, Taylor and Boser recognise how emotional stress in situations of adversarial power relations can block attempts to be reflexive. They ask:

How do we nurture ourselves and others during such times? What strategies enable us to maintain openness to learning during periods of conflict and stress? And what are the implications for the role of, and necessary skills for, leadership in participatory processes?

In an article that includes reflecting on their personal experience of confronting power in their own organisations, the authors conclude that the development of trust and working cooperatively rather than in an adversarial manner, is key to altering power relations.

\section{Conclusion: knowing power}

In the introduction to her article and reflecting on her growing up in Jamaica, Moncrieffe considers the dual role of power to which we referred at the start of this introduction, and in that respect considers Bourdieu's theme of misrecognition:

Power, in practice, can be repressive and even lend itself to violence; conversely, power is crucial for producing healthy changes in social relations, such as would profit those subsisting in conditions of poverty or those subjected to various forms of injustice; repressive power is most potent and durable when people accept and uphold the (mis)perceptions and conditions that underpin their own inequality; therefore, much hinges on the extent to which, in the emerging social contexts, people are adequately challenged to recognise, confront and transform the socially acquired dispositions that allow for repression, both of others and of themselves.

How can a team of researchers and teachers knowledge specialists - contribute to this challenge, bearing in mind Pettit's discussion of how our own lives are full of contradictions and that we are ourselves often failing to confront our 'socially acquired dispositions' that reproduce injustice?

One way to confront these dispositions is to address issues of power in our everyday professional practice within our own organisations, as discussed by Taylor and Boser. A further way is for team members to work with those whom Chambers has called 'lowers' to support them to reconceptualise their own power positions and work with them to help improve their capacity to develop power within and power with. Yet another could be to take up Chambers' challenge of working with 'uppers' to support them in ceding power or, to express it more felicitously, sharing it. Harris' work with men in Mali and elsewhere is a case in point.

Not all members of the team would necessarily support all of these options. But all understand knowledge as a resource in the power field and, as Gaventa and Cornwall stress in their article, seek to make the production of knowledge more democratic. ${ }^{2}$ Therefore, a diversity in understanding and approaches within our own team is an expression of the importance we place on there being no single way of understanding the world or of promoting social justice. This reflects a commitment to help others find their own understandings rather than having power (understood in the Foucauldian sense as discipline) interpret the world for them in a way that is disempowering.

Thus, the contributions to this IDS Bulletin and the ways in which power is interrogated are very varied, despite a shared commitment to exploring its meaning for social change. In categorising power in the way we have, our intention has not been to offer a comprehensive or exclusive framework for analysing power. Rather, in our presentation of the argument, we have sought to construct a positive spiral between reflection and transformation, concluding that the role of the action researcher/teacher is to explore with others - students, activists, practitioners, policymakers and communicators - as to how power can be harnessed for change and to work alongside them in tracing and learning from the myriad of micro level efforts, successes and failures.

Other than in Hunter's discussion of the state and the scope for legal activism in renegotiating the concepts of public and private domains, missing from this collection of articles is any central analysis of power in terms of the connections between the diffuse operations of power in society and the formal political institutions that reflect, reproduce and potentially contribute to changing power. It is worth noting that 
the Participation, Power and Social Change team also hosts the Development Research Centre on Citizenship, Participation and Accountability and in its new cycle of work, one of the Centre's three research themes relates to how new democratic institutions and new patterns of activism open political opportunities for people to express their interests and negotiate in political arenas. $A$ second theme concerns how violence shapes relations between states and their citizens (not just as individuals but also as community and family members).

Nevertheless, over and above this work in the Citizenship research programme, the editors believe

\section{Notes}

* The editors are most grateful to Dee Donlan for her consistent and committed support in chasing the contributors, for constructive editing of the drafts and overall for helping this IDS Bulletin see the light of day.

1 Ladbury, S. (2006) 'An independent review of two IDS programmes - 'Repositioning Participation'

\section{References}

Arendt, H. (2003) 'What is Authority?', in P. Baehr (ed.), The Portable Hannah Arendt, New York: Penguin Books: 462-507

De Certeau, M. (1988) The Practice of Everyday Life, Berkeley, CA: University of California

DFID (2006) Unpublished invitation for expressions of interest in relation to a new Research Programme Consortium, Department for International Development

Harris, C. (2004) Control and Subversion: Gender Relations in Tajikistan, London: Pluto Press

Haugaard, M. (2003) 'Reflections on Seven Ways of Creating Power', European Journal of Social Theory 6.1: 87-113

Haugaard, M. (1997) The Constitution of Power, Manchester: Manchester University Press

Hayward, C. (2000) Defacing Power, Cambridge: Cambridge University Press

Hindess, Barry (1996) Discourses of Power: From Hobbes to Foucault, Oxford: Blackwell

IDS Annual Report 2004-05, Brighton: IDS: 4

Klouda, T. (2004) 'Thinking Critically, Speaking Critically', unpublished paper there remains a challenge for the team as a whole in expanding our own knowledge of power so as not to be constrained by conventional theoretical and disciplinary distinctions. In particular, we might want to go further along the road that Hunter has indicated, exploring how power shapes citizens' constructions of state institutions and the potential role of these institutions, including development organisations, in harnessing public power as a counterbalance to patriarchal and other forms of oppressive societal power within families and local communities. Thus, we ask our readers both to engage with this work in progress and to encourage us to go further.

and 'Power, Participation and Change', unpublished report.

2 Work elsewhere in IDS, particularly within the Knowledge, Technology and Society team, has also been exploring these themes.

Lovell, T. (2003) 'Resisting with Authority: Historica Specificity, Agency and the Performative Self', Theory, Culture and Society 20.1: 1-17

Mosse, D. (2005) 'Power Relations and Poverty Reduction', in R. Alsop (ed.), Power, Rights and Poverty: Concepts and Connections, Washington DC and London: World Bank / DFID: 51-67

Mouffe, C. (1997) 'Feminism, Citizenship and Radical Politics', in J. Butler and J.W. Scott (eds) Feminists Theorize the Political, New York: Routledge Rowlands, J. (1997) Questioning Empowerment: Working with Women in Honduras, Oxford: Oxfam

Saxena, N., Shah, T. and Chambers, R. (1989) To the Hands of the Poor: Water and Trees, New Delhi: Oxford and $\mathrm{IBH}$ Publishing, and London: Intermediate Technology Publications

Scott, J. (1987) Weapons of the Weak, Newhaven, CT: Yale University Press

Veneklasen, L. with Miller, V. (2002) A New Weave of Power, People and Politics, Oklahoma: World Neighbours: 39-57 